\title{
In-Service Degradation of Metallurgical and Mechanical Properties of Aluminized Coatings and Substrates in Gas Turbine Blades
}

\author{
Akihiro Ito $^{1}$, Kazuhiro Sugiyama ${ }^{1}$, Nobuo Shinohara ${ }^{1}$, Yuji Sugita ${ }^{1}$, \\ Shigeo Sakurai ${ }^{2}$ and Jun Kameda ${ }^{3}$ \\ ${ }^{1}$ Electric Power Research and Development Center, Chubu Electric Power Co., Inc., Nagoya 459-8522, Japan \\ ${ }^{2}$ Mechanical Engineering Research Laboratory, Hitachi Ltd., Hitachi 317-8511, Japan \\ ${ }^{3}$ Ames Laboratory, Iowa State University, Ames 50011, USA
}

\begin{abstract}
In-service degradation of metallurgical and mechanical properties of aluminized CoCrAlY coatings and Ni-base superalloy substrates in advanced gas turbine blades has been studied. The aluminized coatings of the unexposed and in-service exposed blades consisted of four layers with different microstructure and chemical composition. In-service environmental attack led to the deposition of Fe oxides on the top aluminized coating and formation of a thin-layered $\mathrm{Al}_{2} \mathrm{O}_{3}$. While in-service, Ni diffused extensively from the substrate into the near-surface coating region. The interdiffusion of $\mathrm{Co} / \mathrm{Ni}$ resulted in the formation of $\mathrm{Al} / \mathrm{Ni}$ rich precipitates in all the coating regions, except a near-surface coating region indicating $\mathrm{Cr}$ rich precipitates. A number of $\mathrm{Cr}$ rich precipitates were found in the substrate near the interdiffusion zone. The near-interface coating region and substrate softened at room and elevated temperatures. The ductility and low cycle fatigue life of the internal coating region at room temperature was not degraded. However, the ductility of the internal and near-interface coating regions and substrate at elevated temperatures was substantially degraded. In-service mechanical degradation of the aluminized CoCrAlY coatings is discussed in light of the metallurgical evolution.
\end{abstract}

(Received August 6, 2001; Accepted November 14, 2001)

Keywords: gas turbine, blade, coating, nickel-base superalloy, degradation, small punch test, mechanical property

\section{Introduction}

The application of the combined cycle power plant has been extending because of its high thermal efficiency, flexibility in operation and superior suitability to environment. Advanced gas turbine blades are operated for a long-term under high thermal stresses and elevated temperature oxidizing environments. Aluminized coatings have been applied over Ni-base superalloy substrates to improve the resistance of advanced blades to elevated temperature environmental attack. ${ }^{1,2)}$ The formation of Al rich phases near the coating surface would mitigate the oxidation. However, the degradation of blade coatings and substrates, which influence the gas turbine integrity, inevitably occurs in-service. ${ }^{3)}$ Microstructural and compositional change in the coatings of in-service exposed blades has been extensively studied. ${ }^{4,5)}$ It is difficult to examine mechanical degradation of coatings, which is required to ensure the performance of blades. This is due to the difficulty in examining mechanical properties of coatings localized near the surface in complex shaped blades by the use of standard testing methods.

The present authors have applied a small punch (SP) testing method in conjunction with scanning Auger microscope (SAM) analysis to examine in-service degradation of blade coatings. ${ }^{6,7)}$ Demonstrating the different extent of mechanical degradation in blade coatings has proved the applicability of the methodology. In-service degradation of mechanical properties and microstructure has been shown in $\mathrm{CoNiCrAlY}$ and unaluminized CoCrAlY coatings of blades under combustion of combined fuels of liquefied natural gas (LNG) and kerosene or under combustion of LNG. ${ }^{6-8)}$ Recent studies have clarified variations of mechanical properties in layered structure of aluminized CoCrAlY coatings in advanced blades. $^{9,10)}$ Moreover, the effect of thermal ageing for $8000 \mathrm{~h}$ in air on the aluminized coatings has been studied. ${ }^{11)}$

This paper attempts to investigate how in-service exposure under combustion of LNG affects metallurgical and mechanical properties under monotonic and cyclic loading in the aluminized CoCrAlY coatings of blades. The results of the inservice exposed blade are compared with those of the unexposed one. In-service mechanical degradation of the internal and near-interface aluminized coatings is also discussed.

\section{Experimental Procedure}

\subsection{Materials and specimens}

First stage gas turbine blades, which have been made up of aluminized CoCrAlY coatings over directionally solidified (DS) Ni-base superalloy substrates, were used in this paper. The CoCrAlY coatings had been deposited by a lowpressure plasma spray method and subsequently aluminized using a pack-diffusion treatment. ${ }^{1,5)}$ The chemical composition of CoCrAlY coatings and Ni-base superalloy substrates in this study are given in Table 1 . The coating thickness varied from 200-250 $\mu \mathrm{m}$ depending on the location of the blade. The blade studied was exposed in-service for $17298 \mathrm{~h}$ under combustion of LNG, and experienced 97 starts and stops. A $70-80 \%$ airfoil height of the pressure side near the tailing edge of the blade was examined, as shown in Fig. 1.

\subsection{Test methods}

SAM specimens ( $3 \mathrm{~mm}$ wide, $2 \mathrm{~mm}$ thick and $10 \mathrm{~mm}$ long) and disk-shaped SP specimens $(6 \mathrm{~mm} \phi$ and $0.5 \mathrm{~mm}$ thick) were machined, taken from the near-surface region in the blades. The coating was located on a side of the SAM and SP specimens. The surface of coated SP specimens was lo- 
Table 1 Chemical composition of CoCrAlY coatings and substrates studied.

\begin{tabular}{|c|c|c|c|c|c|c|c|c|c|c|c|c|}
\hline $\mathrm{Ma}$ & & $\mathrm{Ni}$ & Co & $\mathrm{Cr}$ & $\mathrm{Al}$ & $\mathrm{Ti}$ & $\mathrm{C}$ & B & Mo & W & $\mathrm{Ta}$ & $\mathrm{Y}$ \\
\hline \multirow{2}{*}{ Coating } & mass $\%$ & - & Bal. & 29 & 6 & - & - & - & - & - & - & 0.5 \\
\hline & at $\%$ & - & Bal. & 29.7 & 11.8 & - & - & - & - & - & - & 0.3 \\
\hline \multirow{2}{*}{ Substrate } & mass $\%$ & Bal. & 9.5 & 14 & 3 & 4.9 & 0.1 & 0.01 & 1.5 & 3.8 & 2.8 & - \\
\hline & at $\%$ & Bal. & 9.3 & 15.5 & 6.41 & 5.9 & 0.48 & 0.05 & 0.9 & 1.19 & 0.89 & - \\
\hline
\end{tabular}

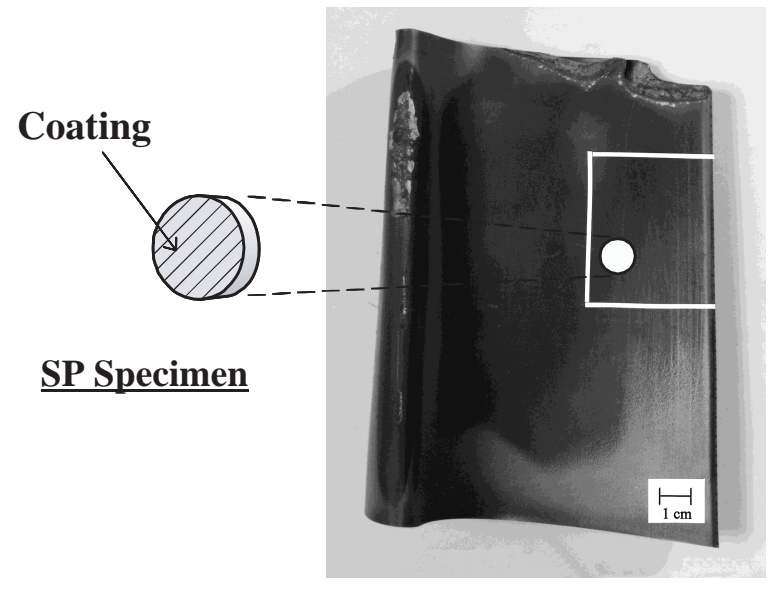

\section{$\underline{\text { Pressure Side }}$}

Fig. 1 Extraction of disk-shaped SP specimens from gas turbine blades.

cated in the internal and near-interface coating regions. Substrate SP specimens were made by machining off the coatings and a coating/substrate interdiffusion zone. The surface of the SAM and SP specimens was polished using emery paper (1000 grit) and/or $\mathrm{Al}_{2} \mathrm{O}_{3}$ powders. Longitudinal sections of the SAM specimen were sputter-cleaned in Ar gas atmosphere $\left(5 \times 10^{-6} \mathrm{~Pa}\right)$. Scanning electron microscopy (SEM) micrographs and SAM elemental maps of the sputtercleaned surfaces were taken using a cylindrical mirror analyzer $(5 \mathrm{keV})$ of Physical Electronics Model 660. The size of electron beams used was about $0.1 \mu \mathrm{m}$. SAM elemental maps were taken corresponding to the SEM micrographs. The first derivative Auger peak height of various elements at selected spots was acquired in a survey or multiplex mode. The concentration of elements was estimated from the measured Auger signal intensity and the relative sensitivity factor of elements. ${ }^{12)}$

The setup for SP testing and method of measuring the deflection using a linear voltage capacitance transducer (LVCT) are schematically shown in Fig. 2. Coated and substrate SP specimens were placed into a lower die and clamped using an upper die with four screws. SP specimens were deformed using a puncher with a hemispherical tip to ensure that the coatings would be subject to tensile applied stresses. SP tests were carried out in air at room temperature (RT), $870^{\circ} \mathrm{C}$ and $950^{\circ} \mathrm{C}$ using a crosshead speed of $8 \times 10^{-6} \mathrm{~m} / \mathrm{s}$ in a screw-driven Instron testing machine. The SP specimen, puncher and holder were heated by an induction coil. The temperature of the SP specimen was controlled by a thermocouple attached to the lower die. A load vs. deflection curve was recorded during

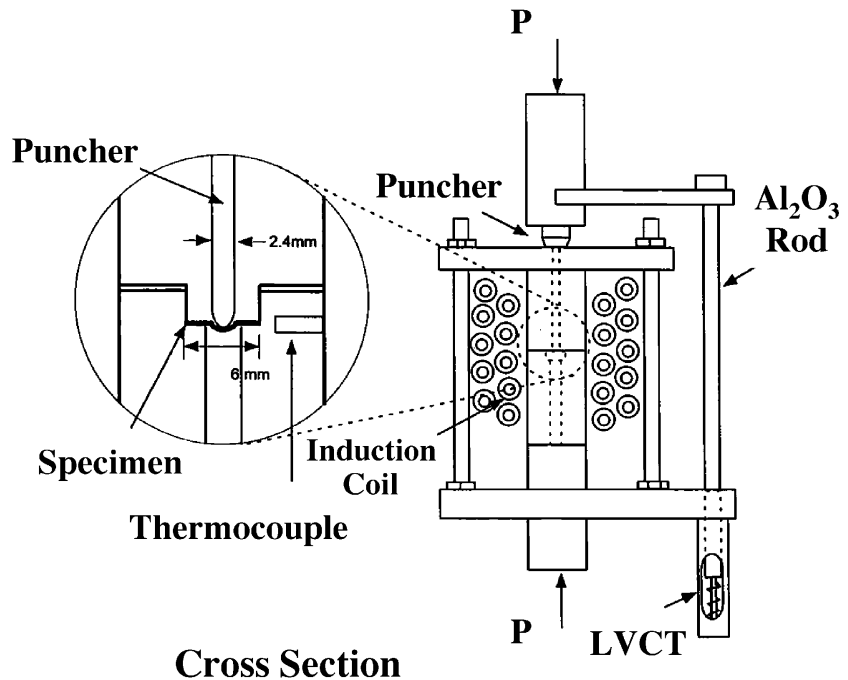

Fig. 2 Schematic drawing of setup for SP testing and measuring method of deflection by LVCT.

the punch loading via a computer. In the flow curve obtained from the SP tests, the yield strength $\left(\sigma_{y}\right)$ can be determined from the yield load $\left(P_{y}\right)$ defined at the transition point from the elastic to plastic bending deformation regime. ${ }^{13)}$ The onset of brittle cracks was detected by a decrease in the loading rate at the critical deflection $\left(\delta_{f}\right)$ in the flow curve. The value of the critical deflection required for ductile cracking at elevated temperatures was estimated by SEM observation of load-interrupted SP specimens. The ductility $\left(\varepsilon_{f}\right)$ of the coatings was defined at the crack initiation and estimated from the critical deflection $\left(\delta_{f}\right)$ and the specimen thickness. ${ }^{14,15)}$ Low cycle fatigue (LCF) of SP tests at RT in the coating were performed under cyclic loading of the frequency of $0.1 \mathrm{~Hz}$. The variation of the load range $\left(\Delta P=P_{\max }-P_{\min }\right)$ was measured as a function of the number of cycle under the constant deflection $\left(R=P_{\min } / P_{\max }<0.05\right)$. The initiation of LCF cracks gave rise to a drop of the load range. Then we defined the LCF life $\left(N_{f}\right)$ of the coatings at the crack initiation. The strain range $(\Delta \varepsilon)$ of the coatings was estimated from the deflection range $(\Delta \delta)$ and the specimen thickness. ${ }^{6,11)}$ The details of SP tests and LCF-SP tests have been presented separately. ${ }^{6-11)}$

\section{Results}

\subsection{Metallurgical features}

Figure 3 shows optical micrographs on cross sections of the unexposed $^{9,10)}$ and in-service exposed blades. Extensive microstructural change in the coating occurred while in-service. As shown in Fig. 3, the aluminized coatings of the unex- 
(a)

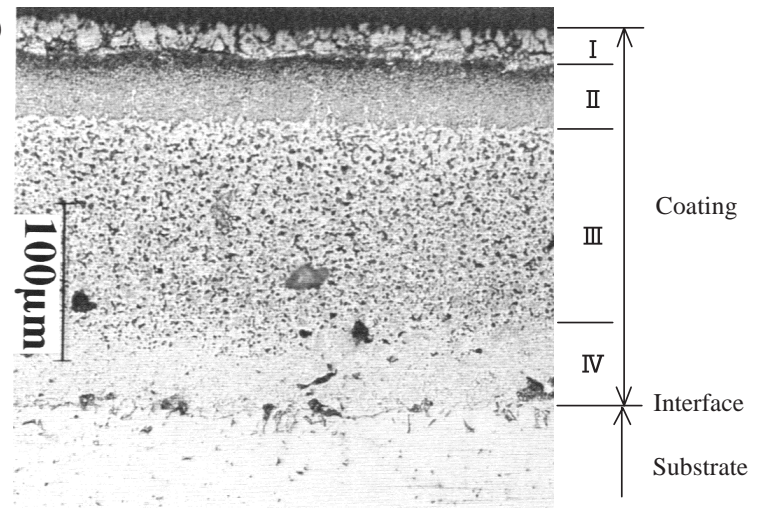

(b)

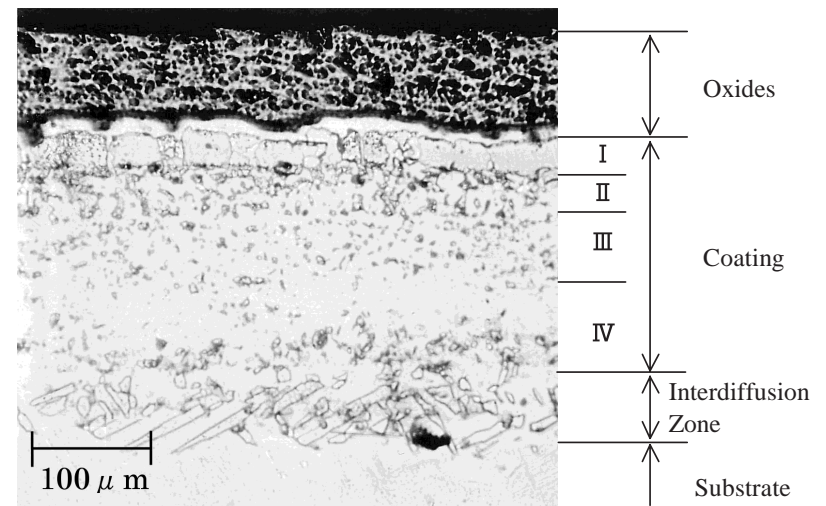

Fig. 3 Optical micrographs on cross sections of gas turbine blades. (a) Unexposed blade. (b) In-service exposed blade.

posed and in-service exposed blade had layered microstructure divided into four regions designated as I-IV. Coating regions I and II are located near the surface, and coating regions III and IV represent internal and near-interface coatings. Compared to the unexposed coating, in-service exposure resulted in obscuring the regions III and IV. As mentioned later, the regions III and IV were determined based on the result of microstructure and composition analysis. The environmental attack and microstructural change of the aluminized CoCrAlY coatings induced while in-service were examined by SAM analysis. Figure 4 shows a SEM micrograph and SAM elemental maps of $\mathrm{Co}, \mathrm{Cr}, \mathrm{Al}, \mathrm{Ni}, \mathrm{Fe}$ and $\mathrm{O}$ on the cross section of the in-service exposed blade. Figures 5 and 6 show SEM micrographs and SAM elemental maps near the surface and coating/substrate interface, respectively. Profiles of chemical composition of $\mathrm{Co}, \mathrm{Cr}, \mathrm{Al}$ and $\mathrm{Ni}$ across coatings and near-interface substrates of the unexposed ${ }^{10)}$ and in-service exposed blades are shown in Fig. 7. As shown in Fig. 4, in-service exposure led to the deposition of Fe oxides, which might have come from the compressor stages, on the top aluminized coating and formation of a thin-layered $\mathrm{Al}_{2} \mathrm{O}_{3}$ $(<10 \mu \mathrm{m})$ between the Fe oxides and region I. The thickness of Fe oxides was about $70 \mu \mathrm{m}$.

The microstructure of the coating in the unexposed blade reported previously is as follows. ${ }^{9,10)}$ In the region I, Cr was replaced by $\mathrm{Al}$ to form an $\mathrm{Al}$ rich intermetallic phase during the aluminizing treatment. The region II had graded composition of $\mathrm{Al}$ and $\mathrm{Cr}$ with a slight drop of Co content. The internal coating region III had the dispersion of fine $\mathrm{Al}$ rich precipitates and coarse $\mathrm{Cr}$ rich precipitates in the coating matrix with the nominal composition. The region IV adjacent to the interface resulted from the interdiffusion of $\mathrm{Co} / \mathrm{Ni}$ between the coating and substrate.

On the other hand, Ni diffused extensively from the substrate into the near-surface region I during in-service exposure, as shown in Figs. 4-6. The region I of the in-service exposed blade remained high $\mathrm{Al}$ contents. Thus, an $\mathrm{Al}$ rich phase in the region I of the unexposed blade transformed to the mixture of an $\mathrm{Al} / \mathrm{Ni}$ rich phase and the coating matrix while in-service. In the region II of the in-service exposed blade, coarse $\mathrm{Cr}$ rich precipitates dispersed. In the internal coating region III of the in-service exposed blade, coarse $\mathrm{Al} / \mathrm{Ni}$ rich precipitates distributed sparsely in the matrix, but $\mathrm{Cr}$ rich precipitates were not observed. In the region
IV, in-service exposure produced the microstructure consisting of $\mathrm{Al} / \mathrm{Ni}$ rich precipitates in the coating matrix. $\mathrm{Al} / \mathrm{Ni}$ rich precipitates distributed more sparsely than in the region III, except near the interdiffusion zone. The $\mathrm{Co} / \mathrm{Ni}$ interdiffusion gave rise to the formation of an interdiffusion zone with the size of about $60 \mu \mathrm{m}$ in the substrate adjacent to the interface of the in-service exposed blade. The interdiffusion zone comprised elongated $\mathrm{Al} / \mathrm{Ni}$ rich precipitates. A number of $\mathrm{Cr}$ rich precipitates were found just ahead of the interdiffusion zone/substrate boundary.

\subsection{Mechanical properties}

The results of SP tests for the unexposed and thermally aged blades have shown that the near-surface coating regions (I and II), made up of $\mathrm{Al}$ and $\mathrm{Cr}$ rich phases, exhibited brittle cracking readily at room and elevated temperatures. ${ }^{9-11)}$ There is a need to examine the mechanical properties of the internal and near-interface coating regions to examine the integrity of advanced blades while in-service, since near-surface cracking would occur readily in the aluminized coatings. Therefore, the SP specimens were sectioned so as to locate the surface in the internal coating region III or nearinterface coating region IV.

Figure 8 shows the comparison of the yield strength at RT, $870^{\circ} \mathrm{C}$ and $950^{\circ} \mathrm{C}$ in the coating regions III, IV and substrate of the unexposed and in-service exposed blades. As shown in Fig. 8, the region IV and substrate of the in-service exposed blade softened at room and elevated temperatures. Thus, in-service exposure produced softening in the near-interface coating regions and substrate at room and elevated temperatures. However, the yield strength at room and elevated temperatures in the region III of the in-service exposed blade did not decrease.

Figure 9 shows the comparison of the ductility at RT, $870^{\circ} \mathrm{C}$ and $950^{\circ} \mathrm{C}$ in the coating regions III, IV and substrate of the unexposed and in-service exposed blades. As shown in Fig. 9, the in-service exposed blade showed lower ductility in the regions III, IV and substrate than the unexposed one. Increasing the testing temperature improved the ductility more dramatically in the region III of the unexposed blade than in that of the in-service exposed one. A large drop occurred in the region III and substrate of the in-service exposed blade tested at high temperatures. However, the ductility at RT in the region III of the in-service exposed blade did not decrease. Thus, in- 
(a)
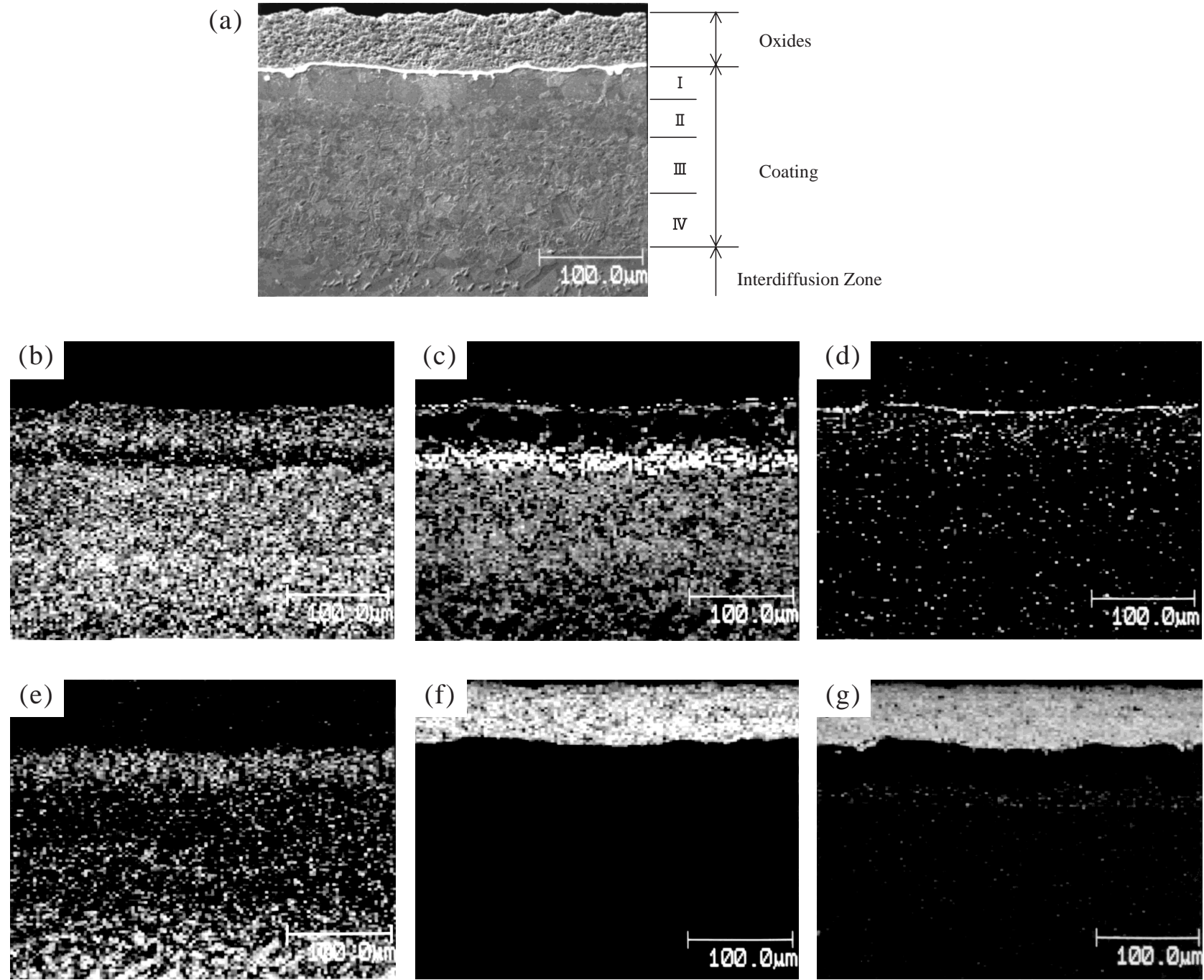

Fig. 4 SEM micrograph and SAM elemental maps on cross section of in-service exposed blade. (a) SEM micrograph. (b) Co, (c) Cr, (d) $\mathrm{Al},(\mathrm{e}) \mathrm{Ni}$, (f) $\mathrm{Fe}$ and (g) O maps.

service exposure exerted a detrimental effect on the ductility in the internal, near-interface coating regions and substrate at elevated temperatures.

The morphology of cracking in coated SP specimens of the in-service exposed blade at room and elevated temperatures in air was examined and compared with that of the unexposed one. In the regions III and IV of all the blades, brittle cracks initiated at the center of SP specimens and propagated along the radial direction at RT. In the regions III and IV of the unexposed blade, transgranular cracks extended discontinuously at elevated temperatures. Multiple cracks were observed in the regions III and IV of the in-service exposed blade at room and elevated temperatures. The grain boundary fracture mode was observed in the regions III and IV of the in-service exposed blade tested at high temperatures, showing low ductility.

The LCF behavior at RT was studied in the region III of the unexposed and in-service exposed blades. The variation of the load range to the number of cycles was measured under the constant deflection. The initiation of LCF cracks gave rise to a drop of the load range. Then the LCF life of the coatings was defined as the number of cycles when the load range reaches $98 \%$ of the maximum load range. The LCF life at RT was shown in Fig. 10. As shown in Fig. 10, the LCF life in the internal coating region III of the in-service exposed blade almost remained the same as that of the unexposed one. The logarithmic plot between the number of cycles to cracking $\left(N_{f}\right)$ and strain range $(\Delta \varepsilon)$ suggests an empirical relationship, i.e., $\Delta \varepsilon \cdot N_{f}^{0.32}=2.4$. It must be pointed out that the LCF data at $N_{f}=1$ extrapolating the LCF line is coincident with the ductility data (indicated by an asterisk mark) at RT in Fig. 9.

\section{Discussion}

By applying SAM analysis and SP testing method, the present study has shown how in-service exposure influences metallurgical and mechanical properties in the layered structure of aluminized CoCrAlY coatings of blades. It was found that while the aluminized coatings had excellent oxidation resistance, in-service exposure produced large changes in the microstructure and chemical composition of the various regions in the coating. The regions III, IV and substrate of the in-service exposed blade had a large ductility loss at room and elevated temperatures.

Based on the phase diagrams of ternary $\mathrm{Co}-\mathrm{Cr}-\mathrm{Al}$ and 

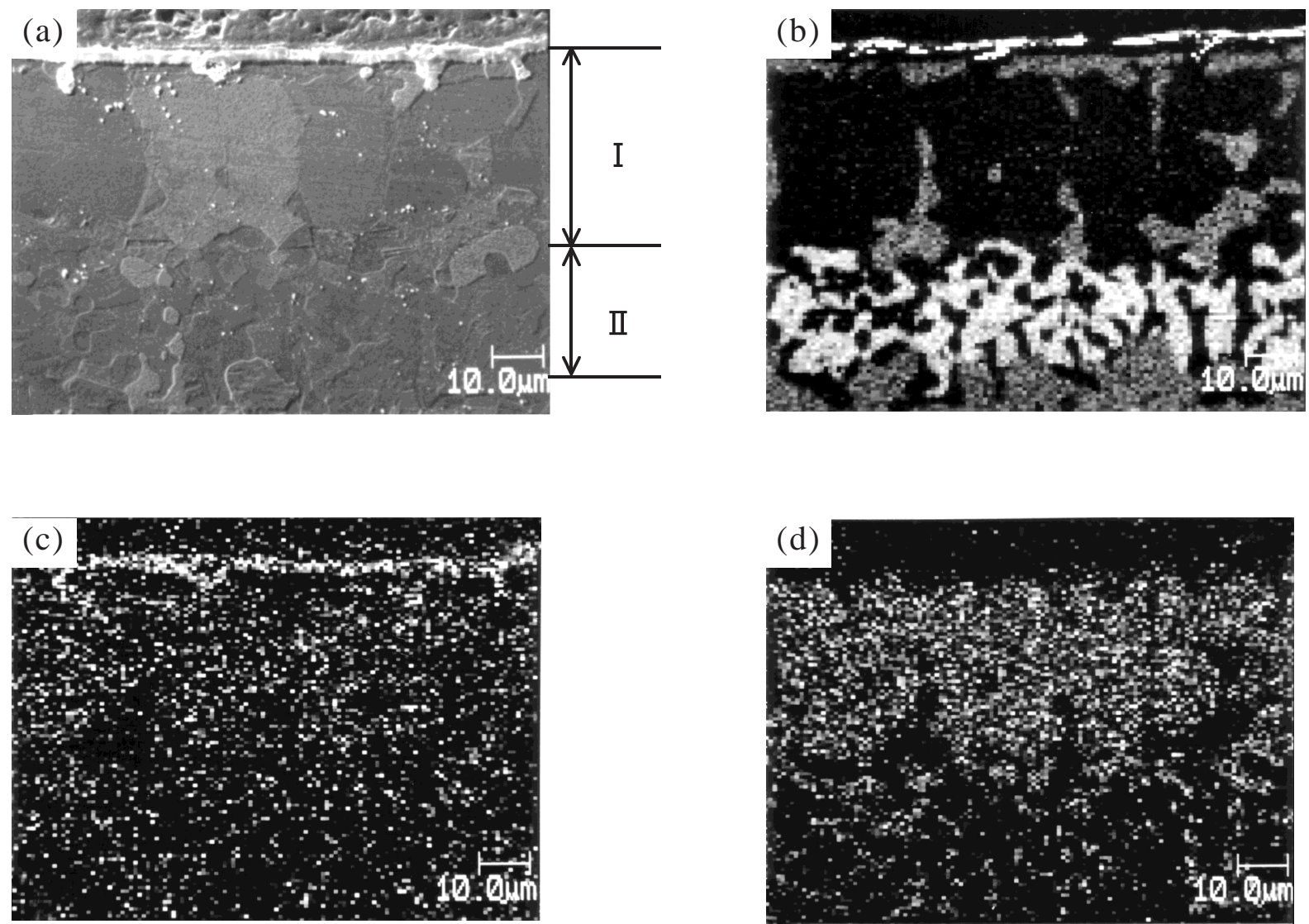

Fig. 5 SEM micrograph and SAM elemental maps near surface on cross section of in-service exposed blade. (a) SEM micrograph. (b) $\mathrm{Cr}$, (c) $\mathrm{Al}$ and (d) Ni maps.

Co-Ni-Al alloys ${ }^{16)}$ and binary $\mathrm{Co}-\mathrm{Al}$ and $\mathrm{Co}-\mathrm{Cr}$ alloys, ${ }^{17)}$ the microstructure and composition observed in the various coating regions (I-IV) of the unexposed and in-service exposed blades are discussed. The solute $\mathrm{Al}$ content of the nearsurface coating region I must decrease during in-service exposure because of the formation of $\mathrm{Al}_{2} \mathrm{O}_{3}$ on the top aluminized coating. On the other hand, the inward diffusion of $\mathrm{Al}$ due to the concentration gradient was not significant. The region I of the in-service exposed blade remained a sufficient Al content. In the region II of the in-service exposed blade, a coarse $\mathrm{Cr}$ rich phase, presumably $\sigma-\mathrm{CoCr},{ }^{5)}$ dispersed in the matrix. According to the ternary $\mathrm{Co}-\mathrm{Cr}-\mathrm{Al}$ phase diagram, $\mathrm{Al}$ and Co depletion and $\mathrm{Cr}$ enrichment are expected to give rise to the formation of the $\sigma$ phase in the region II of the in-service exposed blade. Fine $\mathrm{Al}$ rich and coarse $\mathrm{Cr}$ rich precipitates in the internal coating region III of the unexposed blade may $\beta$-CoAl and $\sigma$ phases, respectively. ${ }^{2-5)}$ In the region III of the in-service exposed blade, the dispersion of $\mathrm{Cr}$ rich precipitates was not observed. The in-service exposed blade resulted in only $\mathrm{Al} / \mathrm{Ni}$ rich precipitates, presumably $\beta$ phase ${ }^{3-5)}$ in the region III. On the other hand, the $\sigma$ phase has not been reported in any coating region of an in-service exposed blade when the unaluminized CoCrAlY coatings were given. ${ }^{8)}$ The reason of the difference in the precipitation of the $\sigma$ phase is not certain.

Based on the analysis of the microstructural and compositional change in the various coating regions, the in-service exposed blade has more similarities to the thermally aged at $920^{\circ} \mathrm{C}$ blade than the thermally aged at $870^{\circ} \mathrm{C}$ one. ${ }^{11,18)}$ Since the duration of thermal exposure time of the in-service exposed blade was two times longer than that of the thermally aged at $920^{\circ} \mathrm{C}$ one, the in-service exposed blade had a larger size of the interdiffusion zone. The size of interdiffusion zone is proportional to the square root of the exposure or ageing duration. ${ }^{5)}$ We found that the size ratio of the interdiffusion zone of the in-service exposed blade to that of the thermally aged at $920^{\circ} \mathrm{C}$ one is 1.4 . The actual temperature that in-service exposed blades experience is a subject of concerns. From the above figure, the in-service exposed temperature would be estimated to be about $920^{\circ} \mathrm{C}$, which is consistent with the result by Ellison et al. ${ }^{5 \text { ) }}$

As shown in Fig. 9, the coating and substrate of the inservice exposed blade had lower ductility at room and elevated temperatures, compared to that of the unexposed one. These findings could be related not only to metallurgical evolution, but also to environmental embrittlement in the case of the SP test that is sensitive to testing environment. ${ }^{7,11)}$ The ductility loss at elevated temperatures in the coating regions III and IV of the in-service exposed blade is related to the distinct dispersion of the $\mathrm{Al} / \mathrm{Ni}$ rich $\beta$ phase and an increase in the $\mathrm{Ni}$ content of the coating matrix phase. In-service exposure resulted in more formation of cracks in the coatings at room and elevated temperatures. The grain boundary fracture mode was observed in the in-service exposed coatings tested at high temperatures, showing low ductility. These results may imply that the in-service exposure would increase the susceptibility of the coatings to oxygen embrittlement. It is well known that Ni-base alloys and $\mathrm{Ni}$ aluminides 

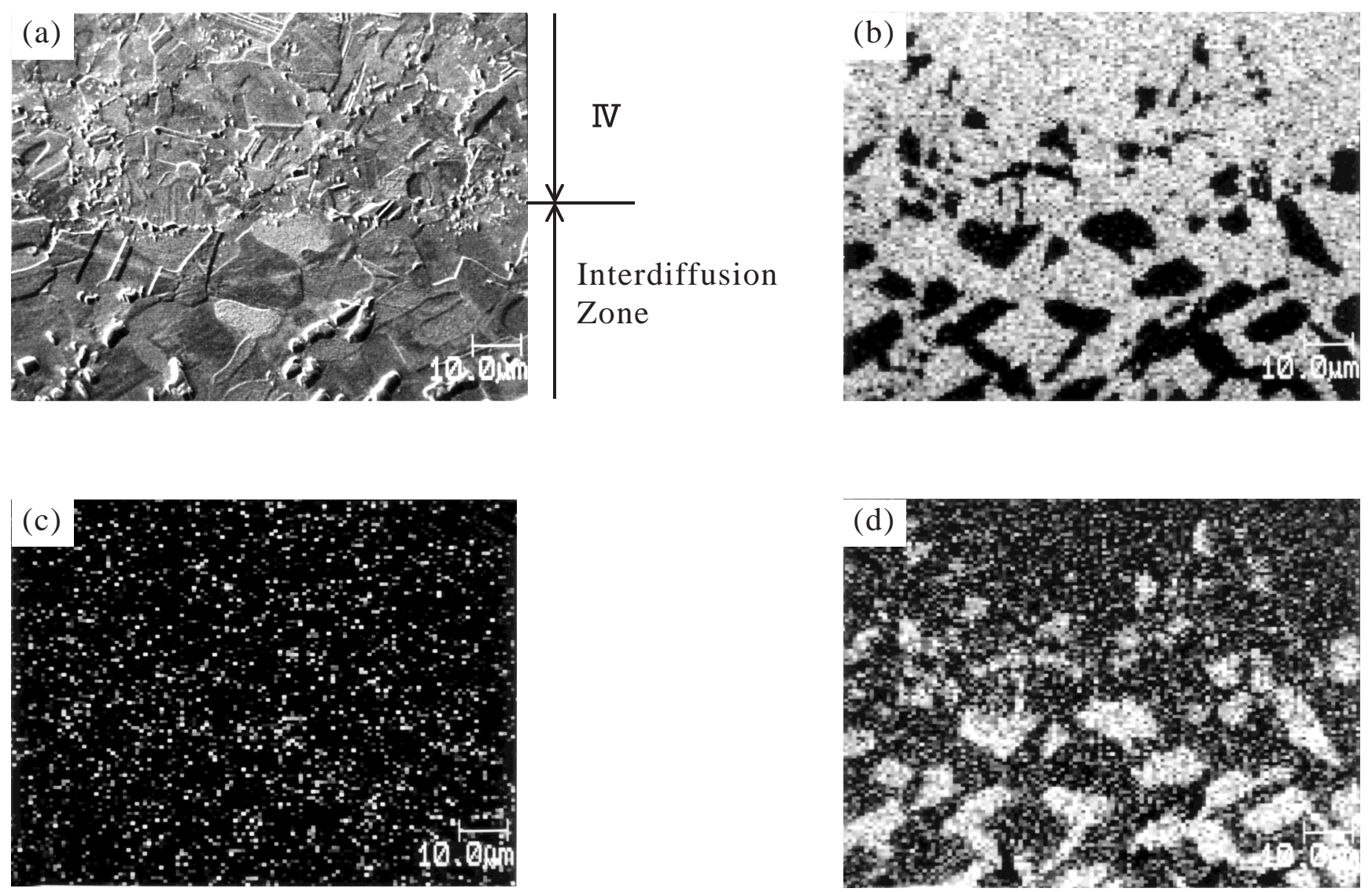

Fig. 6 SEM micrograph and SAM elemental maps near interface on cross section of in-service exposed blade. (a) SEM micrograph. (b) $\mathrm{Cr}$, (c) Al and (d) Ni maps.

have a higher susceptibility to oxygen embrittlement than Cobase alloys. ${ }^{19-21)}$ It is speculated that oxygen diffusion along stressed grain boundaries would promote brittle crack extension by weakening the boundary cohesion.

Land-based gas turbines are frequently subject to the startup and shutdown transient operation. Thus, LCF behavior of coatings plays a critical role in the in-service integrity of blades. The growth of LCF coating cracks gives rise to the exposure of the substrate to elevated temperature environments, thereby degrading the substrate. In this way, the remaining life of blades is controlled by LCF behavior of the coatings. As shown in Fig. 10, the LCF life at RT in the internal coating region III of the in-service exposed blade almost remained the same as that of the unexposed one. It was found that the LCF life of the coatings decreased with decreasing ductility. ${ }^{6,11)}$ Since in-service exposure decreased the ductility at elevated temperatures of the regions III and IV, in-service exposure would cause a reduction in the LCF life at elevated temperatures in the coating regions. SP tests on the unexposed and thermally aged blades have shown that the nearsurface coating regions I and II exhibited very low ductility at room and elevated temperatures. ${ }^{9-11)}$ Therefore, near-surface cracks would occur readily in the coating regions I and II that is caused by thermal and/or applied stresses during in-service exposure. The near-surface cracks in the aluminized coating would propagate into the substrate under monotonic and/or cyclic condition, because the ductility loss of the internal and near-interface coating regions at elevated temperatures would occur while in-service.
Consequently, it is evident that the application of the SP testing method is useful for characterizing in-service mechanical degradation of blade coatings under monotonic and/or cyclic loading conditions.

\section{Conclusions}

Metallurgical and mechanical properties at room and elevated temperatures have been studied in aluminized $\mathrm{CoCrAlY}$ coatings and Ni-base superalloy substrates of gas turbine blades subjected to in-service exposure under combustion of LNG. By means of SAM analysis, it was revealed that inservice environmental attack led to the deposition of Fe oxides on the top of the aluminized coating associated with thin-layered $\mathrm{Al}_{2} \mathrm{O}_{3}$. While in-service, the interdiffusion of $\mathrm{Co} / \mathrm{Ni}$ from the substrate into the coatings resulted in the formation of $\mathrm{Al} / \mathrm{Ni}$ rich precipitates in all the coating regions, except a near-surface coating region indicating $\mathrm{Cr}$ rich precipitates. In the internal coating region, $\mathrm{Cr}$ rich precipitates disappeared. The $\mathrm{Co} / \mathrm{Ni}$ interdiffusion gave rise to the formation of an interdiffusion zone. A number of $\mathrm{Cr}$ rich precipitates were found in the substrate near the interdiffusion zone. SP tests indicated that the near-interface coating region and substrate softened at room and elevated temperatures. The ductility and low cycle fatigue of the internal coating region was not degraded at room temperature. However, in-service exposure substantially degraded the ductility of the internal and near-interface coating regions and substrate at elevated temperatures. Thus, evaluation of the ductility at elevated 
(a)

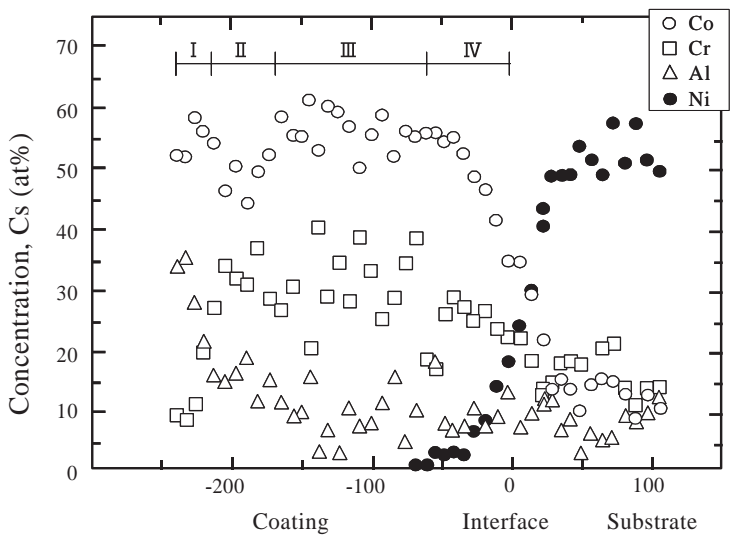

Distance from the Interface, $D / \mu \mathrm{m}$ (b)

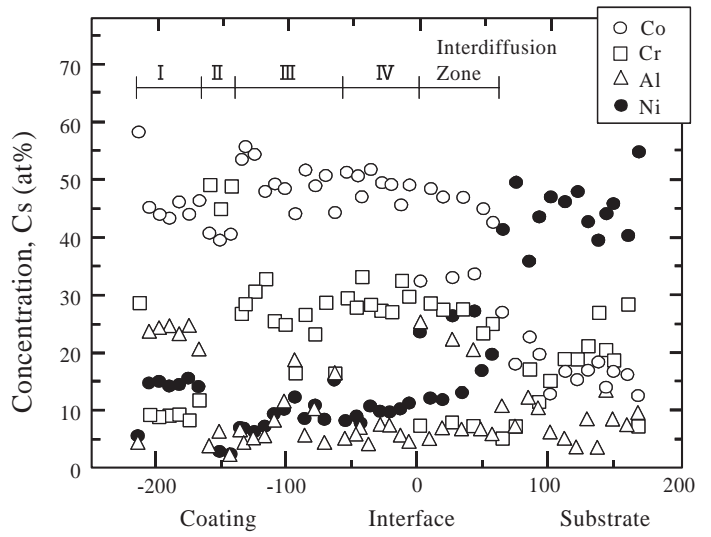

Distance from the Interface, $D / \mu \mathrm{m}$

Fig. 7 Profiles of chemical composition of $\mathrm{Co}, \mathrm{Cr}, \mathrm{Al}$ and $\mathrm{Ni}$ across coatings and substrates near interface. (a) Unexposed blade. ${ }^{10)}$ (b) In-service exposed blade.

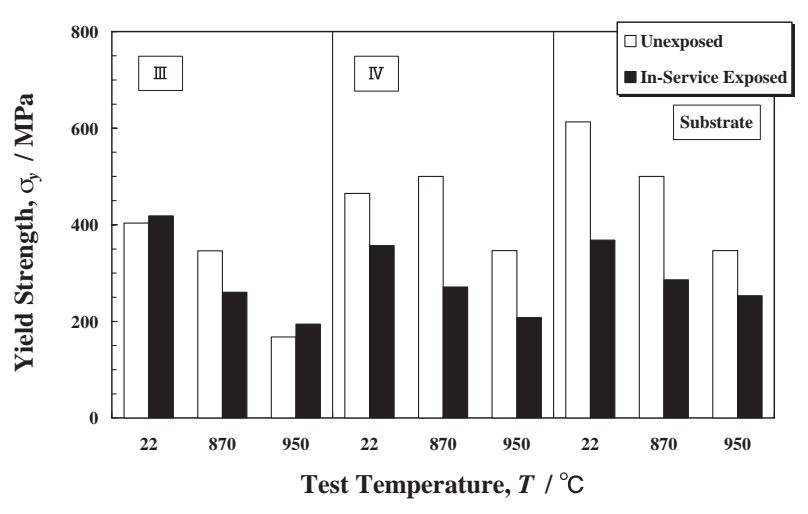

Fig. 8 Comparison of yield strength in coatings and substrates of unexposed and in-service exposed blades.

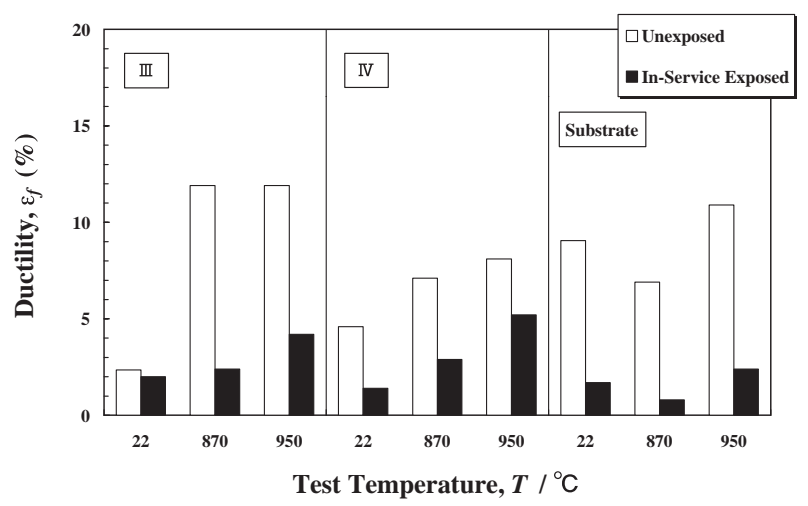

Fig. 9 Comparison of ductility in coatings and substrates of unexposed and in-service exposed blades.

temperatures is a necessary item for life assessment of gas turbine materials.

\section{Acknowledgements}

The authors wish to thank Prof. M. Nagumo of Waseda University for his advice in many aspects on this paper.

\section{REFERENCES}

1) J. R. Rairden III: US Patent, Re 30995 (1982).

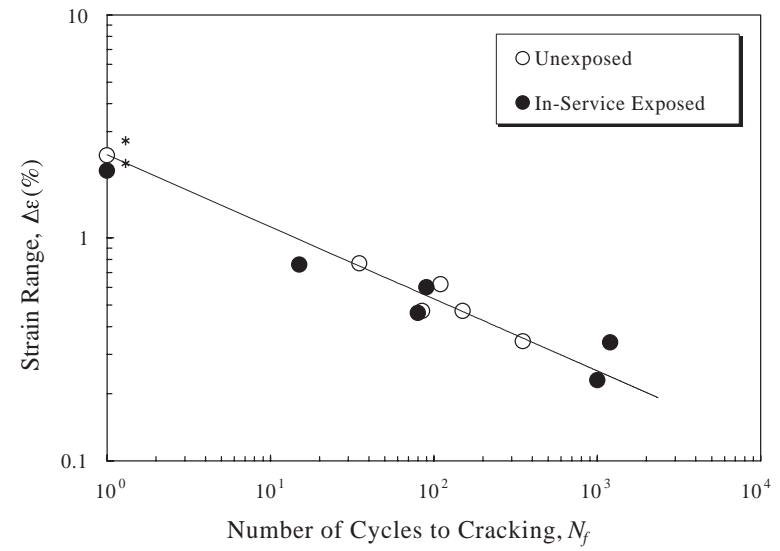

Fig. 10 LCF life at RT in coating region III of unexposed and in-service exposed blades. An asterisk mark indicates ductility.

2) Y. Itoh, M. Saitoh, Y. Harada and J. Takeuchi: J. Soc. Mat. Sci., Japan 44-506 (1995) 1361-1366.

3) J. A. Daleo and D. H. Boone: Proc. Int. Gas Turbine and Aero Engine Congress and Exhibition, (ASME, New York, 1997) 97-GT-486.

4) N. S. Cheruvu and G. R. Leverant: Proc. Int. Gas Turbine and Aero Engine Congress and Exhibition, (ASME, New York, 1998) 98-GT-511.

5) K. A. Ellison, J. A. Daleo and D. H. Boone: Materials for Advanced Power Engineering 5 (1998) 1523-1534.

6) Y. Sugita, A. Ito, S. Sakurai and J. Kameda: Proc. Material Ageing and Component Life Extension, ed. by V. Bicego, A. Nitta and R. Viswanathan (EMAS, West Midland, 1995) pp. 307-316.

7) J. Kameda, T. E. Bloomer, Y. Sugita, A. Ito and S. Sakurai: Mater. Sci. Eng. A 229 (1997) 42-54.

8) J. Kameda, T. E. Bloomer and S. Sakurai: J. Thermal Spray, 8-3 (1999) 440-445.

9) Y. Sugita, A. Ito, S. Sakurai, T. E. Bloomer and J. Kameda: Proc. Int. Gas Turbine and Aero Engine Congress and Exhibition, (ASME, New York, 1997) 97-GT-532.

10) J. Kameda, T. E. Bloomer, Y. Sugita, A. Ito and S. Sakurai: Mater. Sci. Eng. A 234-236 (1997) 489-492.

11) J. Kameda, T. E. Bloomer, Y. Sugita, A. Ito and S. Sakurai: Proc. Int. Gas Turbine and Aero Engine Congress and Exhibition, (ASME, New York, 1998) 98-GT-527.

12) D. Briggs and M. P. Seah: Practical Surface Analysis, (John Willey \& Sons, Chichester, 1983) Chapter 5.

13) J. M. Baik, J. Kameda and O. Buck: Scr. Metall. 17 (1983) 1443-1447.

14) X. Mao and H. Takahashi: J. Nucl. Mater. 150 (1987) 42-52.

15) J. Kameda and X. Mao: J. Mater. Sci. 27 (1992) 983-989.

16) P. Villars, A. Prince and H. Okamoto: Handbook of Ternary Alloy Phase Diagrams, 3 (ASM Int., Materials Park, 1995) pp. 3002-3005, 3052-3062. 
17) T. B. Massalski, H. Okamoto, P. R. Subramanian and L. Kacprzak: Binary Alloy Phase Diagrams, 2 (ASM Int., Materials Park, 1990) pp. 136-138, 1179-1181.

18) A. Ito, Y. Sugita, S. Sakurai and J. Kameda: J. Soc. Mat. Sci., Japan, in press.

19) D. A. Woodford: Proc. Int. Conf. on Life Assessment and Repair Technology for Combustion Turbine Hot Components, ed. by $\mathrm{R}$.
Viswanathan and J. M. Allen (ASM Int., Materials Park, 1990) pp. 97-102.

20) S. T. Wlodek: Proc. Symposium on Long Term Stability of High Temperature Materials, ed. by G. E. Fuchs, K. A. Dannemann and T. C. Deragon (TMS, Warrendale, 1999) pp. 3-40.

21) W. H. Chang: Superalloys-Processing, (Battelle Columbus Laboratories, Columbus, 1972) V1-41. 